Original Research Paper

\title{
Behaviour of Rheology of Nanofluid During Convection in Pipe
}

\author{
Gajanand Yadav and Subrata Kumar Majumder \\ Department of Chemical Engineering, Indian Institute of Technology Guwahati, Guwahati-781039, Assam, India
}

Article history

Received: 11-05-2015

Revised: 09-11-2015

Accepted: 02-01-2016

Corresponding Author: Subrata Kumar Majumder Department of Chemical Engineering, Indian Institute of Technology Guwahati, Guwahati-781039, Assam, India

Email:skmaju@iitg.ernet.in

\begin{abstract}
In this article, the simulation of nanofluid flow in pipe and the behavior of different variables on nanofluid flow are presented. $\mathrm{Al}_{2} \mathrm{O}_{3}$ water of volume fraction of $\mathrm{Al}_{2} \mathrm{O}_{3} 2$ to $8 \%$ was considered as nanofluid for simulation. For the simulation the single phase approach is used to calculate viscosity, temperature difference on wall, Reynolds number, thermal conductivity and temperature throughout the pipe. The MATLAB code is employed to solve the flow in pipe using finite difference method. Finally a conclusion is made based on simulation, how the temperature of the nanofluid flow changed with the radial direction and its axial direction is reported. How thermal conductivity, temperature difference on wall, Reynolds number and the viscosity of the nanofluid changed with the length of the pipe is explained based on the present simulation. Also effects of volume fraction of nanoparticle, radius of pipe, outside temperature of wall, Reynolds number and turbulent flow on the heat flow through pipe.
\end{abstract}

Keywords: Nanofluid, Rheology, Heat Transfer, Simulation, Single-Phase Model

\section{Introduction}

Thermal properties of liquids play a decisive role in heating as well as cooling applications in industrial processes. Thermal conductivity of a liquid is an important physical property that decides its heat transfer performance. Conventional heat transfer fluids have inherently poor thermal conductivity which makes them inadequate for high cooling applications. Scientists have tried to enhance the inherently poor thermal conductivity of these conventional heat transfer fluids using solid additives following the classical effective medium theory (Maxwell, 1873) for effective properties of mixtures. Fine tuning of the dimensions of these solid suspensions to millimeter and micrometer ranges for getting better heat transfer performance have failed because of the drawbacks such as still low thermal conductivity, particle sedimentation, corrosion of components of machines, particle clogging, excessive pressure drop etc. A Nanofluid is a fluid containing nanometer-sized particles, called nanoparticles. These fluids are engineered colloidal suspensions of nanoparticles in a base fluid. The nanoparticles used in nanofluids are typically made of metals, oxides, carbides, or carbon nanotubes. Common base fluids include water, ethylene glycol and oil. Nanofluids have novel properties that make them potentially useful in many applications in heat transfer, including microelectronics, fuel cells, pharmaceutical processes and hybrid-powered engines, engine cooling/vehicle thermal management, domestic refrigerator, chiller, heat exchanger, in grinding, machining and in boiler flue gas temperature reduction. They exhibit enhanced thermal conductivity and the convective heat transfer coefficient compared to the base fluid. Knowledge of the rheological behavior of nanofluids is found to be very critical in deciding their suitability for convective heat transfer applications. The effects of nanoparticle concentrations, nanoparticle diameter, nanoparticle materials and Reynolds number in various flows in rectangular duct and circular pipe in two/three dimensions are described by various authors by simulation. In this regard some literatures are: Akbarinia and Behzadmehr (2007; Heris et al., 2007; Namburu et al., 2009; Fard et al., 2010; Lai and Yang, 2011; Demir et al., 2011; Sasmito et al., 2011; Sarkar et al., 2012; Tahir and Mital, 2012; Akhtari et al., 2013; Sheikholeslami et al., 2013; Celen et al., 2014; Azmi et al., 2014; Zhao et al., 2014; Om and Mohammed, 2014; Beheshti et al., 2015). They studied the effects of nanofluids type, nanoparticle volume fraction of nanofluids and the effect of aspect ratio on the thermal fields. In analysis such as Computational Fluid Dynamics (CFD), nanofluids can be assumed to be single phase fluids. However, almost all of new academic papers use 
two-phase assumption. Classical theory of single phase fluids can be applied, where physical properties of nanofluid are taken as a function of properties of both constituents and their concentrations. There are various numerical studies about convective heat transfer of nanofluids using various types of nanoparticles and base fluids. In numerical study mostly used CFD software to solve equation. The present work is executed on numerical simulation and its analysis of laminar forced convection of nanofluids in a circular tube by MATLAB 2013 with single phase approach.

\section{Theoretical Background}

\section{Model}

The single-phase model considers the nanofluid as a homogenous phase. In this present work only single phase model is considered. The single-phase model has the nanofluid as a homogenous phase. Governing equations (continuity, momentum and energy) are presented by Beheshti et al. (2015) as follows:

Continuity equation:

$\nabla \cdot\left(\rho_{\mathrm{nf}} \mathrm{V}_{\mathrm{m}}\right)=0$

Momentum equation:

$\nabla \cdot\left(\left(\rho_{\mathrm{nf}} \mathrm{V}_{\mathrm{m}}\right) \cdot \mathrm{V}_{\mathrm{m}}\right)=-\nabla \mathrm{P}+\nabla \cdot\left(\mu_{\mathrm{nf}} \nabla \mathrm{V}_{\mathrm{m}}\right)$

Energy equation:

$\nabla \cdot\left(\left(\rho_{\mathrm{nf}} \mathrm{C}_{\mathrm{pnf}} \mathrm{V}_{\mathrm{m}}\right) \cdot \mathrm{T}\right)=\nabla \cdot\left(\mathrm{k}_{\mathrm{nf}} \nabla \mathrm{T}\right)$

The thermal and physical properties:

$$
\begin{aligned}
& \rho_{\mathrm{nf}}=(1-\Phi) \rho_{\mathrm{bf}}+\Phi \rho_{\mathrm{p}} \\
& \mathrm{C}_{\mathrm{pnf}}=\frac{(1-\Phi)\left(\rho \mathrm{C}_{\mathrm{p}}\right)_{\mathrm{bf}}+\Phi\left(\rho \mathrm{C}_{\mathrm{p}}\right)_{\mathrm{p}}}{\rho_{\mathrm{nf}}} \\
& \mu_{\mathrm{nf}}=(1+2.5 \Phi) \mu_{\mathrm{bf}} \\
& \mathrm{k}_{\mathrm{nf}}=\frac{\mathrm{k}_{\mathrm{p}}+2 \mathrm{k}_{\mathrm{bf}}-2\left(\mathrm{k}_{\mathrm{bf}}-\mathrm{k}_{\mathrm{p}}\right) \Phi}{\mathrm{k}_{\mathrm{p}}+2 \mathrm{k}_{\mathrm{bf}}+\left(\mathrm{k}_{\mathrm{bf}}-\mathrm{k}_{\mathrm{p}}\right) \Phi} \mathrm{k}_{\mathrm{b}}
\end{aligned}
$$

\section{Properties of Base Fluid}

The properties of base fluid were calculated based on the correlations developed by Vijay et al. (1982) reported by Ghajar (2005):

$$
\begin{aligned}
& \rho_{\text {bf }}=999.79684+0.068317355 \times \mathrm{T}-0.010740248 \times \mathrm{T}^{2} \\
& +0.00082140905 \times \mathrm{T}^{2.5}-2.3030988 \times 10^{-5} \times \mathrm{T}^{3}
\end{aligned}
$$

$$
\begin{aligned}
\mu_{\mathrm{bf}}= & \frac{1}{557.82468+19.408782 \times \mathrm{T}} \\
& +0.1360459 \times \mathrm{T}^{2}-3.1160832 \times 10^{-4} \times \mathrm{T}^{3}
\end{aligned}
$$

Specific heat capacity:

$$
\begin{aligned}
& \mathrm{C}_{\mathrm{pbf}}=4.2174356-0.0056181625 \times \mathrm{T} \\
& +0.0012992528 \times \mathrm{T}^{1.5}-0.00011535353 \times \mathrm{T}^{4} \\
& +1.724480 \times 10^{-10} \times \mathrm{T}^{5}
\end{aligned}
$$

Thermal conductivity:

$$
\begin{aligned}
& \mathrm{k}_{\mathrm{bf}}=0.5650285+0.0026363895 \times \mathrm{T} \\
& -0.00012516934 \times \mathrm{T}^{1.5}-1.51549180 \times 10^{-6} \times \mathrm{T}^{2} \\
& -0.0009412945 \times \mathrm{T}^{0.5}
\end{aligned}
$$

\section{Heat Transfer Coefficient}

The heat transfer coefficient of water-steel-water is assumed as a constant, because wall temperature is considered a constant value. Since the flow is in laminar condition is considered in the present work, the convective heat transfer coeficient referred to as constant value. It is calculated based on the Sieder and Tate (1936) equation.

\section{Properties of Nanoparticle $\mathrm{Al}_{2} \mathrm{O}_{3}$}

Density, viscosity, specific heat capacity and thermal conductivity are assumed as constant, because the percentage of nanofluids is very less ( 2 to $5 \%$ ). So we calculated temperature effect only for base fluid. The properties of nanoparticle are considered for the present study is given as follows.

For nanoparticle Alumina:

- $\quad$ Thermal conductivity $=46 \mathrm{~W} / \mathrm{m} . \mathrm{K}$

- Density $=3970 \mathrm{~kg} / \mathrm{m}^{3}$

- $\quad$ Specific heat capacity $=760 \mathrm{~J} / \mathrm{kg} . \mathrm{K}$

- $\quad$ Particle diameter $=25 \mathrm{~nm}$

- Volume $\%=2$

\section{Geometric Model}

It is assume that the flow and heat transfer in a horizontal tube could be simplified to a two dimensional model as shown in Fig. 1 because the tube is axial symmetry and gravity can be neglected. The dimensions of the geometry are as follows:

- $\quad$ Radius of pipe $=25 \mathrm{~mm}$

- $\quad$ Length of pipe $=0.5 \mathrm{~m}$

The inlet temperature is considered is equal to $50^{\circ} \mathrm{C}$. 
Solving the governing equation: Continuity equation: We assumed that velocity change only in $\mathrm{Z}$ direction (length wise) and its function of radius only and fully developed laminar flow. So $V_{r}=0, V_{q}=0$ and $V_{z}=V_{z}(r)$.

Momentum equation:

$-\frac{\mathrm{dP}}{\mathrm{dz}}+\mu\left(\frac{1}{\mathrm{r}} \frac{\mathrm{d}}{\mathrm{dr}}\left(\mathrm{r} \frac{\mathrm{dV}_{\mathrm{z}}}{\mathrm{dr}}\right)\right)=0$

Solving these two equations, one gets:

$$
\mathrm{V}_{\mathrm{z}}=\frac{\Delta \mathrm{PR}^{2}}{4 \mu \mathrm{L}}\left(1-\left(\frac{\mathrm{r}^{2}}{\mathrm{R}^{2}}\right)\right)
$$

Energy balance equation: In energy equation we assume that viscosity term can be neglect:

$$
\begin{aligned}
& \rho \mathrm{C}_{\mathrm{p}} \mathrm{V}_{\mathrm{z}} \frac{\mathrm{dT}}{\mathrm{dz}}=\mathrm{k}\left[\frac{1}{\mathrm{r}} \frac{\mathrm{d}}{\mathrm{dr}}\left(\mathrm{r} \frac{\mathrm{dT}}{\mathrm{dr}}\right)+\frac{\mathrm{d}^{2} \mathrm{~T}}{\mathrm{dz}^{2}}\right] \\
& +\mu\left(\frac{\mathrm{dV}_{\mathrm{z}}}{\mathrm{dr}}\right)^{2}+\mathrm{V}_{\mathrm{z}}\left(-\frac{\mathrm{dP}}{\mathrm{dz}}+\mu\left(\frac{1}{\mathrm{r}} \frac{\mathrm{d}}{\mathrm{dr}}\left(\mathrm{r} \frac{\mathrm{dV}_{\mathrm{z}}}{\mathrm{dr}}\right)\right)\right)
\end{aligned}
$$

Use finite difference method to solve difference equation:

$$
\begin{aligned}
& \frac{\mathrm{dT}}{\mathrm{dz}}=\frac{(\mathrm{T}(\mathrm{r}, \mathrm{z})-\mathrm{T}(\mathrm{r}, \mathrm{z}-1))}{\Delta \mathrm{z}} \\
& \frac{\mathrm{d}^{2} \mathrm{~T}}{\mathrm{dz}^{2}}=\frac{(\mathrm{T}(\mathrm{r}, \mathrm{z}+1)-2 \times \mathrm{T}(\mathrm{r}, \mathrm{z}+1)+\mathrm{T}(\mathrm{r}, \mathrm{z}-1))}{\Delta \mathrm{z}^{2}}
\end{aligned}
$$

$\frac{1}{\mathrm{r}} \frac{\mathrm{d}}{\mathrm{dr}}\left(\mathrm{r} \frac{\mathrm{dT}}{\mathrm{dr}}\right)=\frac{(\mathrm{T}(\mathrm{r}+1, \mathrm{z})-2 \times \mathrm{T}(\mathrm{r}, \mathrm{z})+\mathrm{T}(\mathrm{r}-1, \mathrm{z}))}{\Delta \mathrm{r}^{2}}$

$\frac{\mathrm{dV}_{\mathrm{z}}}{\mathrm{dr}}=\frac{\Delta \mathrm{PR}^{2}}{4 \mu \mathrm{L}}\left(-\left(\frac{2 \mathrm{r}}{\mathrm{R}^{2}}\right)\right)$

Assume constants in code:

$$
\mathrm{lr}=\frac{\mathrm{k}_{\mathrm{nf}}}{\Delta \mathrm{r}^{2}} ; \mathrm{lz}=\frac{\mathrm{k}_{\mathrm{nf}}}{\Delta \mathrm{z}^{2}} ; \mathrm{a}=\frac{\Delta \mathrm{PR}^{2}}{4 \mu_{\mathrm{nf}} \mathrm{L}} ; \mathrm{c}=\frac{4 \mu \mathrm{a}^{2}}{\mathrm{R}^{4}} ; \mathrm{ll}=\frac{-\mathrm{a} \rho_{\mathrm{nf}} \mathrm{Cp}_{\mathrm{nf}}}{\Delta \mathrm{z}}\left(1-\frac{\mathrm{r}^{2}}{\mathrm{R}^{2}}\right)
$$

The discretized Equation (14) becomes:

$$
\begin{aligned}
& T(r-1, z) \cdot 1 r+T(r, z-1) \cdot(1 z-1 l z)+T(r, z) \\
& \cdot(1 l z-21 r-2 l z)+T(r, z+1) \cdot 1 z+T(r+1, z) \cdot 1 r=-c \cdot r^{2}
\end{aligned}
$$

Boundary conditions: (i) At $z=0$, for all radius part $\mathrm{T}$ $=50^{\circ} \mathrm{C}$; (ii) At $\mathrm{r}=\mathrm{R},-\mathrm{k} \frac{\mathrm{dT}}{\mathrm{dr}}=\mathrm{h}\left(\mathrm{T}_{\mathrm{R}}-\mathrm{T}_{\text {out }}\right)$; (iii) At $\mathrm{z}=\mathrm{L}$, $-\mathrm{k} \frac{\mathrm{dT}}{\mathrm{dz}}=0$. Outside temperature of pipe is constant $\left(250^{\circ} \mathrm{C}\right)$. Solve with boundary conditions by using finite difference method as: At $r=R$, $(\mathrm{T}(\mathrm{R}-1, \mathrm{z})-\mathrm{T}(\mathrm{R}, \mathrm{z})) / \Delta \mathrm{r}=\mathrm{h}\left(\mathrm{T}(\mathrm{R}, \mathrm{z})-\mathrm{T}_{\text {out }}\right), \quad$ At $\quad \mathrm{z}=\mathrm{L}$ ,$T(r, L)=T(r, L-1)$. Similarly other equations are discretized.

\section{Methodology}

A commercial software package MATLAB 2013 is employed in the numerical study. The problem under investigation is a two-dimensional (axisymmetric) steady, for convection flow of nanofluid flowing inside a straight circular tube. The fluid enters the circular tube with uniform axial velocity and temperature. The flow and thermal fields are assumed to be axisymmetric with respect to the horizontal plane parallel to z-axis as shown in Fig. 1. The geometry is of a horizontal circular tube with a length of $0.5 \mathrm{~m}$ and radius of $25 \mathrm{~mm}$.

\section{Results}

Results have been presented for water based $\mathrm{Al}_{2} \mathrm{O}_{3}$ consisting of $2-10 \%$ volume $\mathrm{Al}_{2} \mathrm{O}_{3}$ spherical shape particles with $25 \mathrm{~nm}$ mean diameter. All walls have been exposed to a uniform temperature. The flow is laminar fully developed in circular cross section. The nanofluid is entered inside at a constant temperature at $50^{\circ} \mathrm{C}$. The temperature profile has uniform along the center axis. The results obtained from the simulations based on different operating variables are shown in Fig. 2-12. The Fig. 2 shows that temperature profile with respect to diameter and length in pipe at $2 \%$ volume friction of nanoparticle. Initial inlet temperature is constant of nanofluid but after enter heating zone temperature has increased. The Fig. 3 shows that thermal conductivity profile with respect to length at 2 to $10 \%$ volume friction of nanoparticle in pipe. Initial rate of increase in thermal conductivity is high because the rate of temperature is high and after that it is decreased. The Fig. 4 shows that viscosity profile with respect to length at 2 to $10 \%$ volume friction of nanoparticle in pipe. The temperature profile has uniform along the center axis as shown in Fig. 5. It is seen that the radius of the pipe has significant effect on viscosity and thermal conductivity as shown in Fig. 6 and 7 respectively. The temperature difference on wall is initially increased with high rate after that rate of change is decreased as shown in Fig. 8. and 9 shows that if the outside temperature is increased, the viscosity is 
decreased. As the outer temperature of pipe increased, the thermal conductivity is increased as shown in Fig. 10. It is seen that the thermal conductivity is decreased with increase in Reynolds number as shown in Fig. 11. At higher Reynolds number, the apparent viscosity is increased which resulted in decrease in thermal conductivity as shown in Fig. 12 for viscosity change with Reynolds number and thermal conductivity change with Reynolds number at a certain distance of the pipe from entry in Fig. 12.

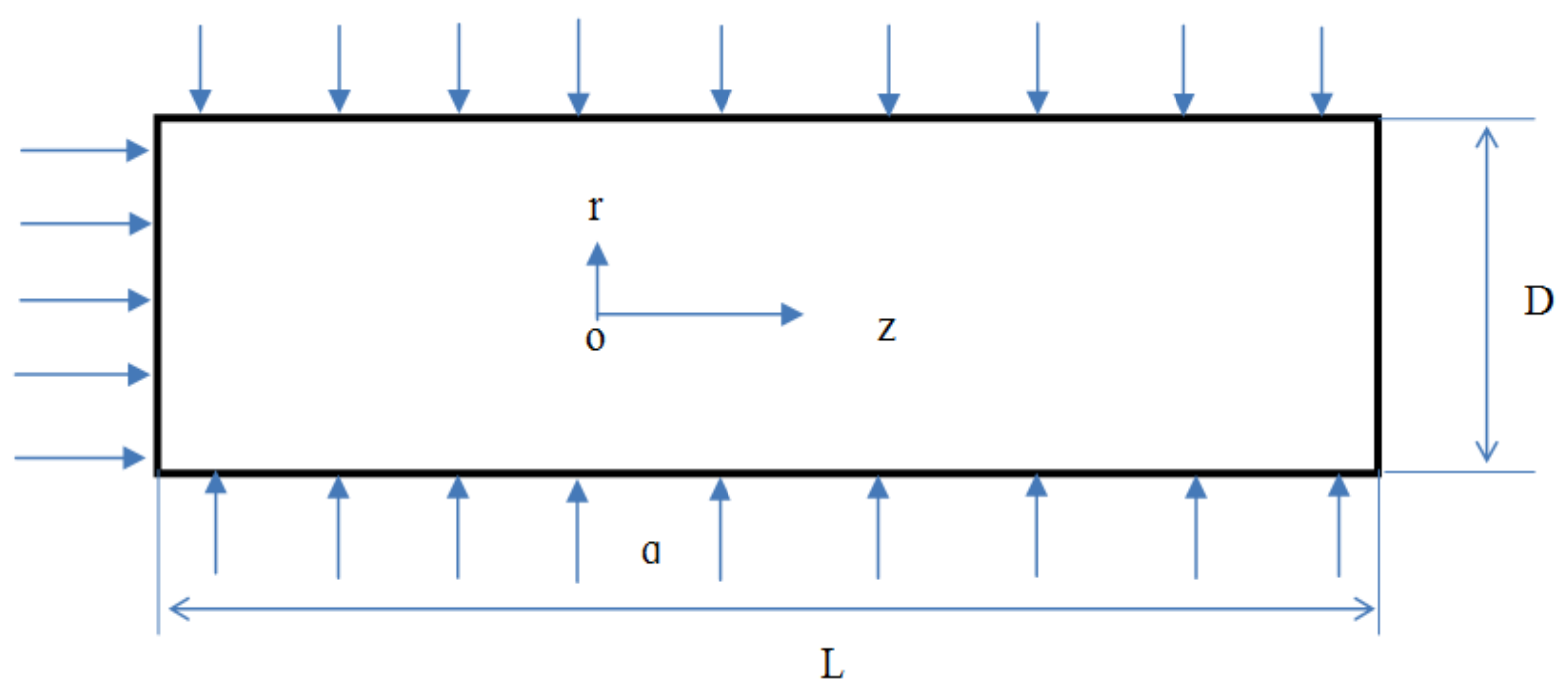

Fig. 1. Nanofluid flow though circular pipe

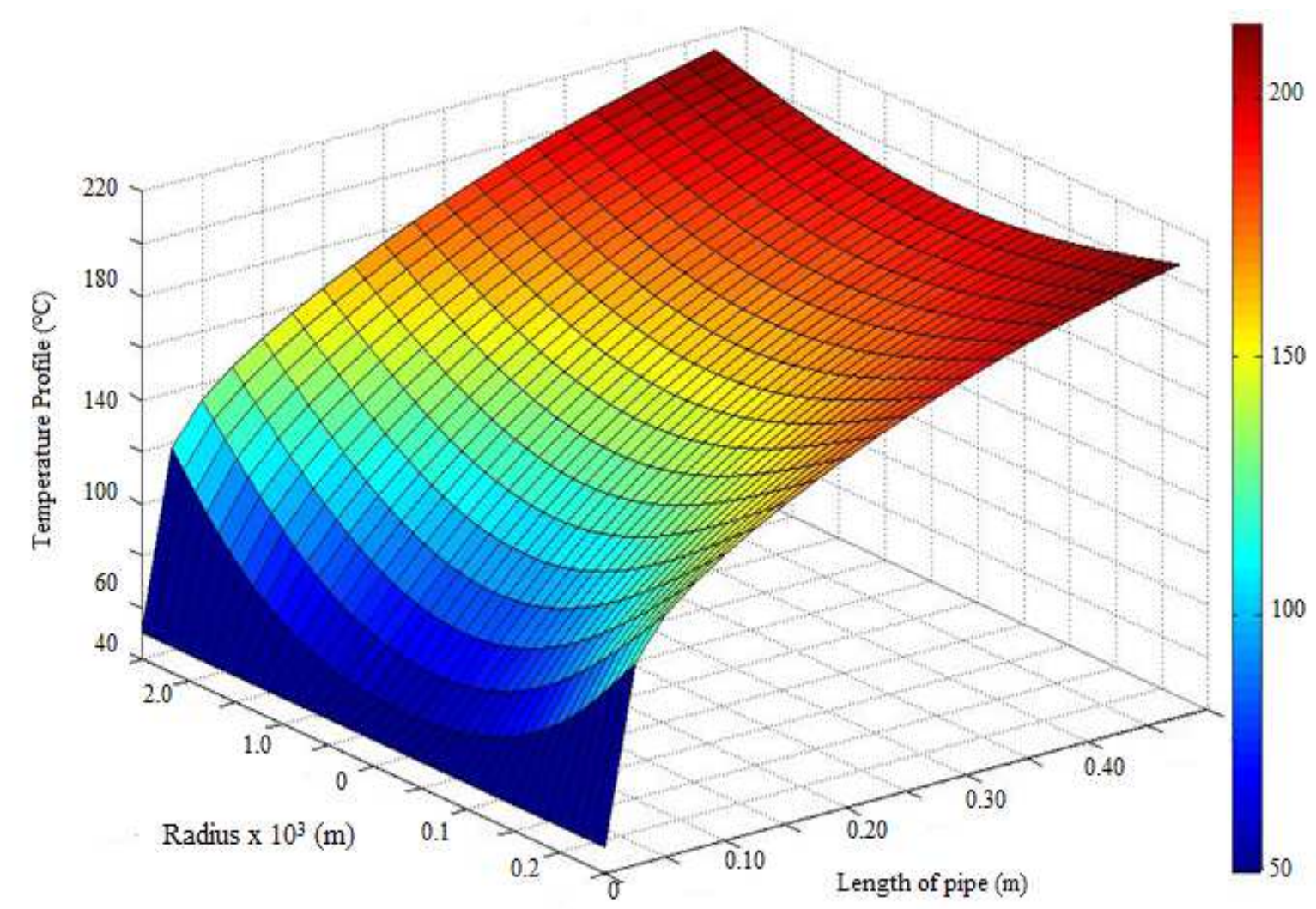

Fig. 2. Temperature profile with length and diameter 


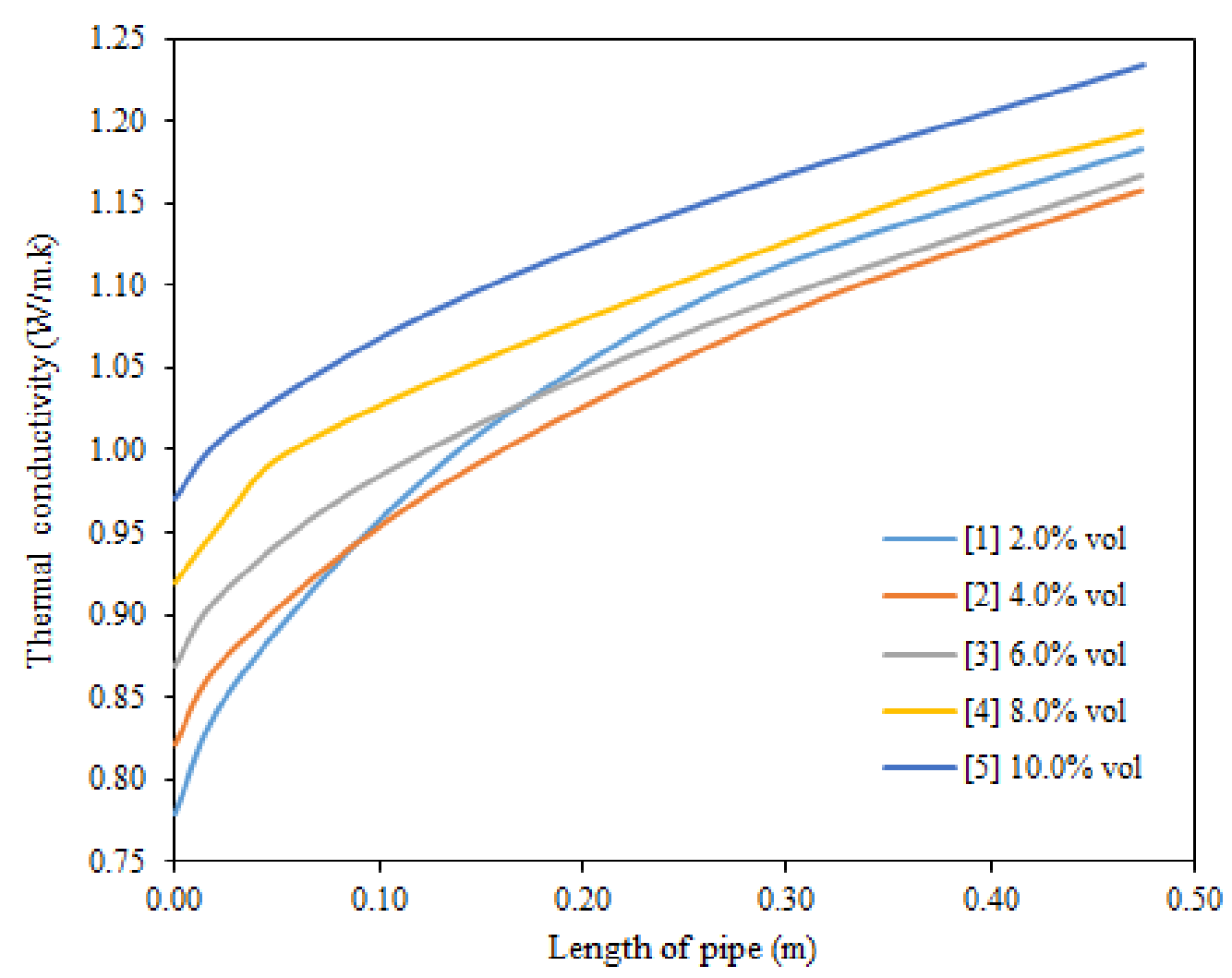

Fig. 3. Thermal conductivity with length at nanoparticle 2 to $10 \%$

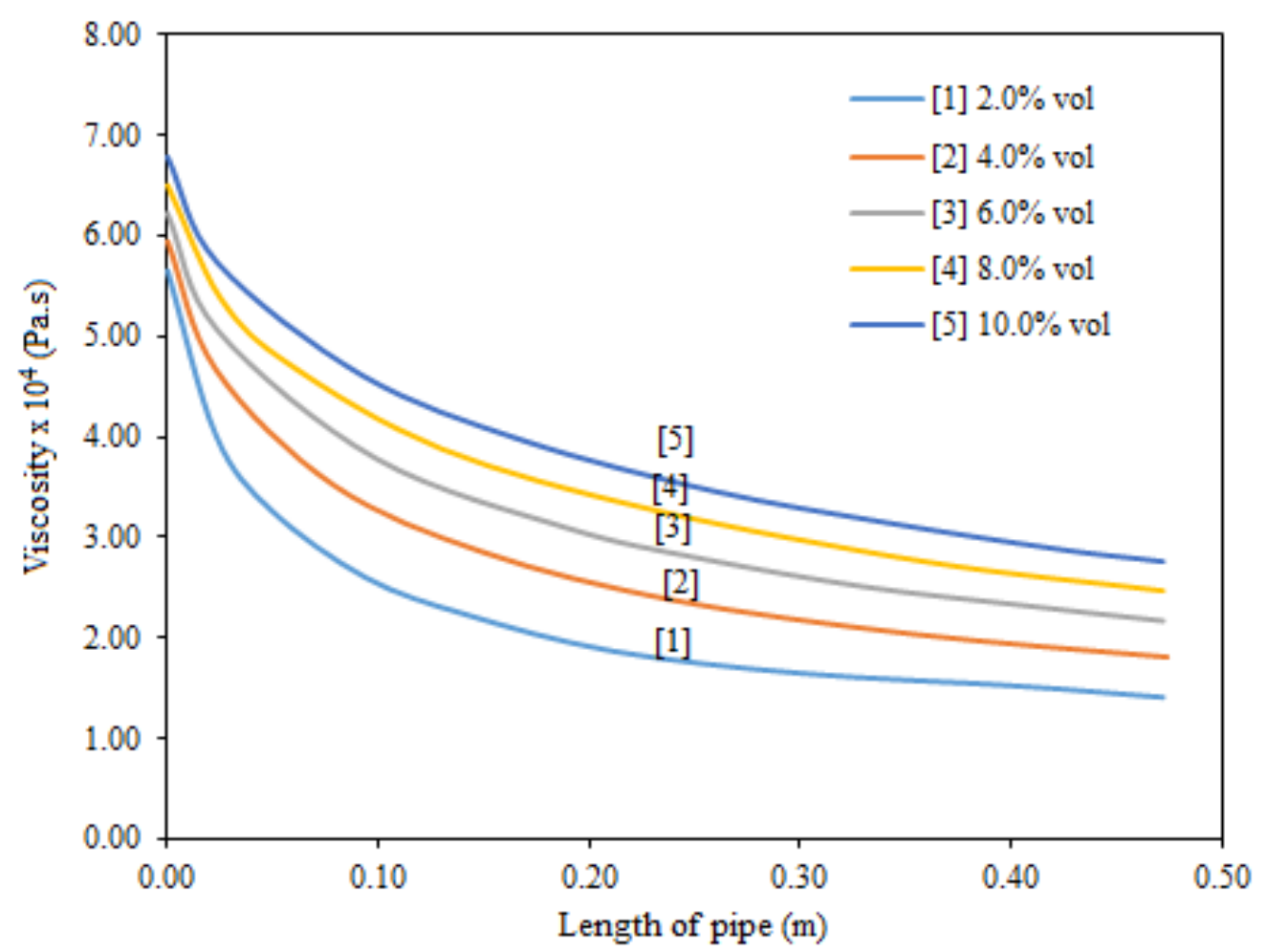

Fig. 4. Viscosity of nanofluids with length 




Fig. 5. Temperature of nanofluids with axes at radius $0.0025 \mathrm{~m}$

\section{Discussion}

\section{The Effect of Length of Pipe on Nanofluid Properties}

Initial rate of increase in temperature is high because the temperature difference between wall and nanofluid are high and after that it decreased as mentioned in Fig. 1. Dispersion of a very small amount of nanoparticle produces a remarkable change in the effective thermal conductivity of the base fluid, with the thermal conductivity ratio exceeding 2-10 volume \% nanoparticles. Initial rate of decrease in viscosity is high because the rate of temperature is high and after that it is decreased.

\section{The Effect of Radius of Pipe}

The fluid enters the circular tube with uniform axial velocity and temperature. The flow and thermal fields are assumed to be axisymmetric with respect to the horizontal plane parallel to $\mathrm{z}$-axis as shown in Fig. 1. Results have been presented for water based $\mathrm{Al}_{2} \mathrm{O}_{3}$ consisting of $4 \%$ volume $\mathrm{Al}_{2} \mathrm{O}_{3}$ spherical shape particles with $25 \mathrm{~nm}$ mean diameter. The geometry is of a horizontal circular tube with a length of $0.5 \mathrm{~m}$ and radius of $25,50,75$ and $1 \mathrm{~cm}$.
All walls have been exposed to a uniform temperature. The flow is laminar fully developed in circular cross section. The nanofluid is entered inside at a constant temperature at $50^{\circ} \mathrm{C}$. The outside temperature of wall is $250^{\circ} \mathrm{C}$. At radius of pipe $=$ $0.025 \mathrm{~m}$ and length of pipe $=0.5 \mathrm{~m}$, initially temperatures change are very fast but at the end, changing in temperatures are less. As we know that thermal conductivity increases with respect to temperature, theincreasingradius resulted temperatures automatically decreased, so thermal conductivity decreased.

\section{The Change of Nanofluids Properties with Outside Temperature of Pipe}

The outside temperatures of wall were considered as $200,250,300$ and $350^{\circ} \mathrm{C}$. The temperature profile is shown in Fig. 8. If the outside temperature is increased, the viscosity is decreased because the temperature is increased as shown in Fig. 9. It is also seen that the thermal conductivity is increased with length at different wall temperature. This is due to decrease in viscosity with increase in outer temperature of the pipe (Fig. 10). 


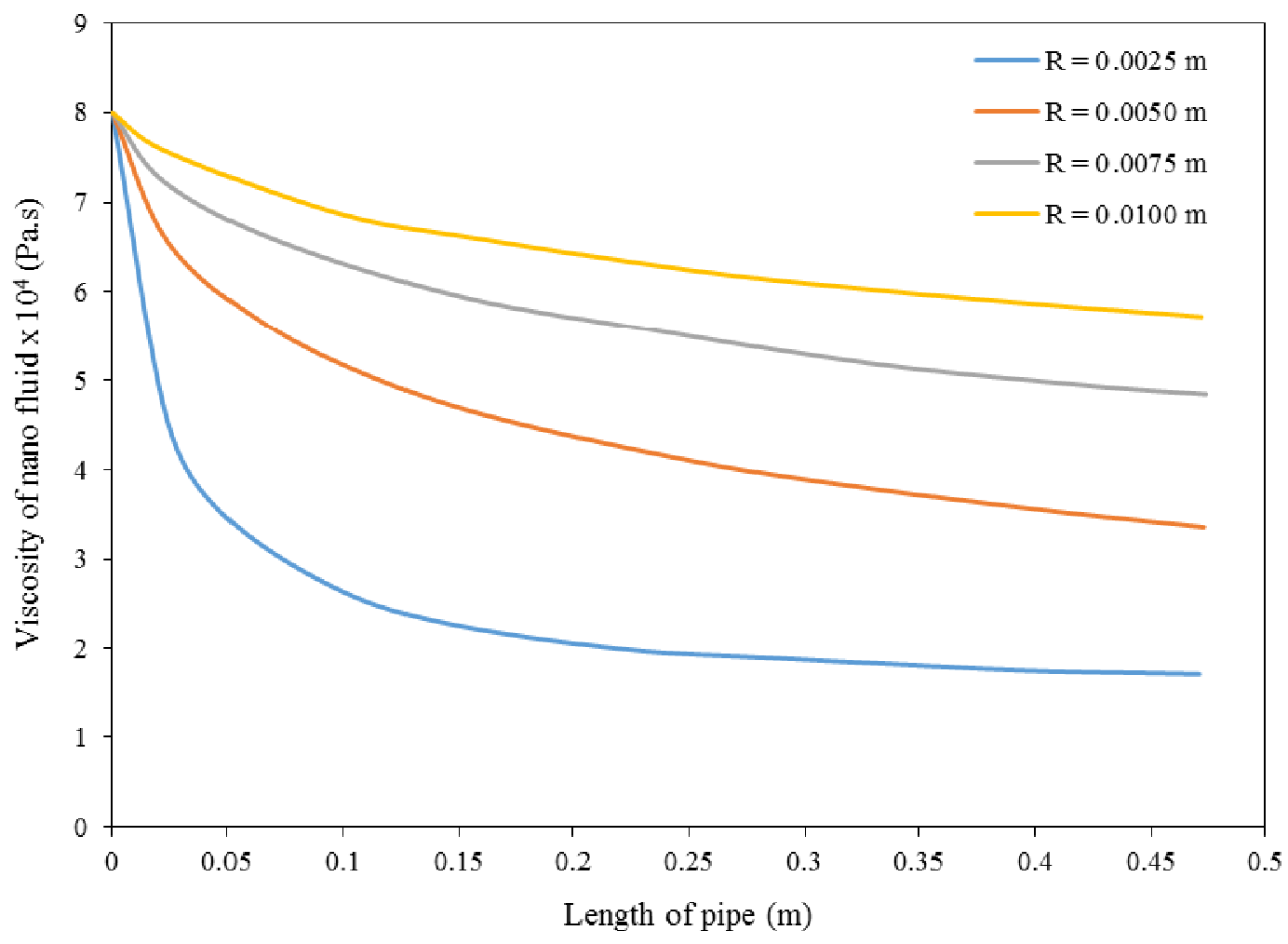

Fig. 6. Viscosity of nanofluids with length

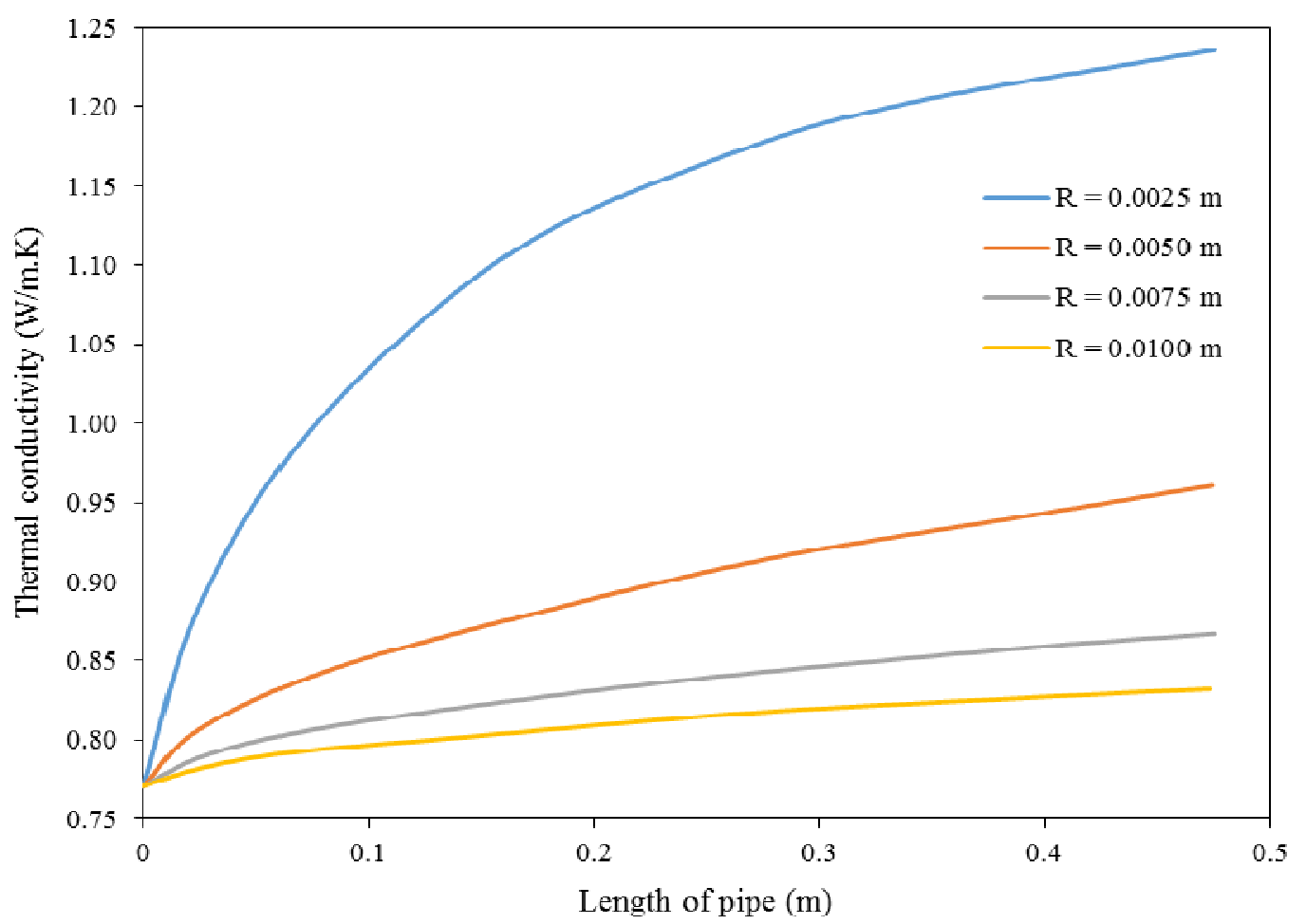

Fig. 7. Thermal conductivity with length 


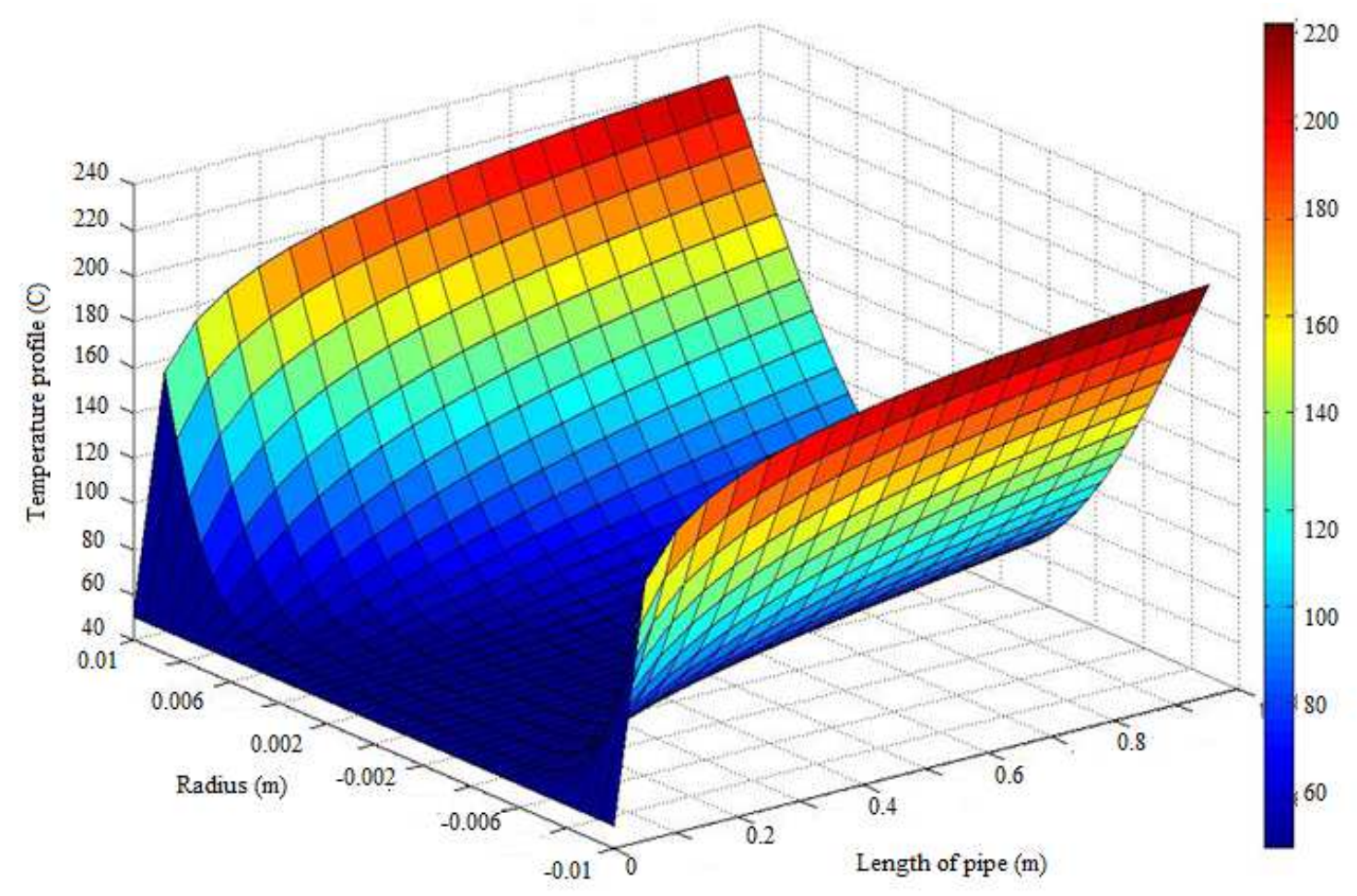

Fig. 8. Temperature of nanofluids with axes at outside wall temperature $=300^{\circ} \mathrm{C}$

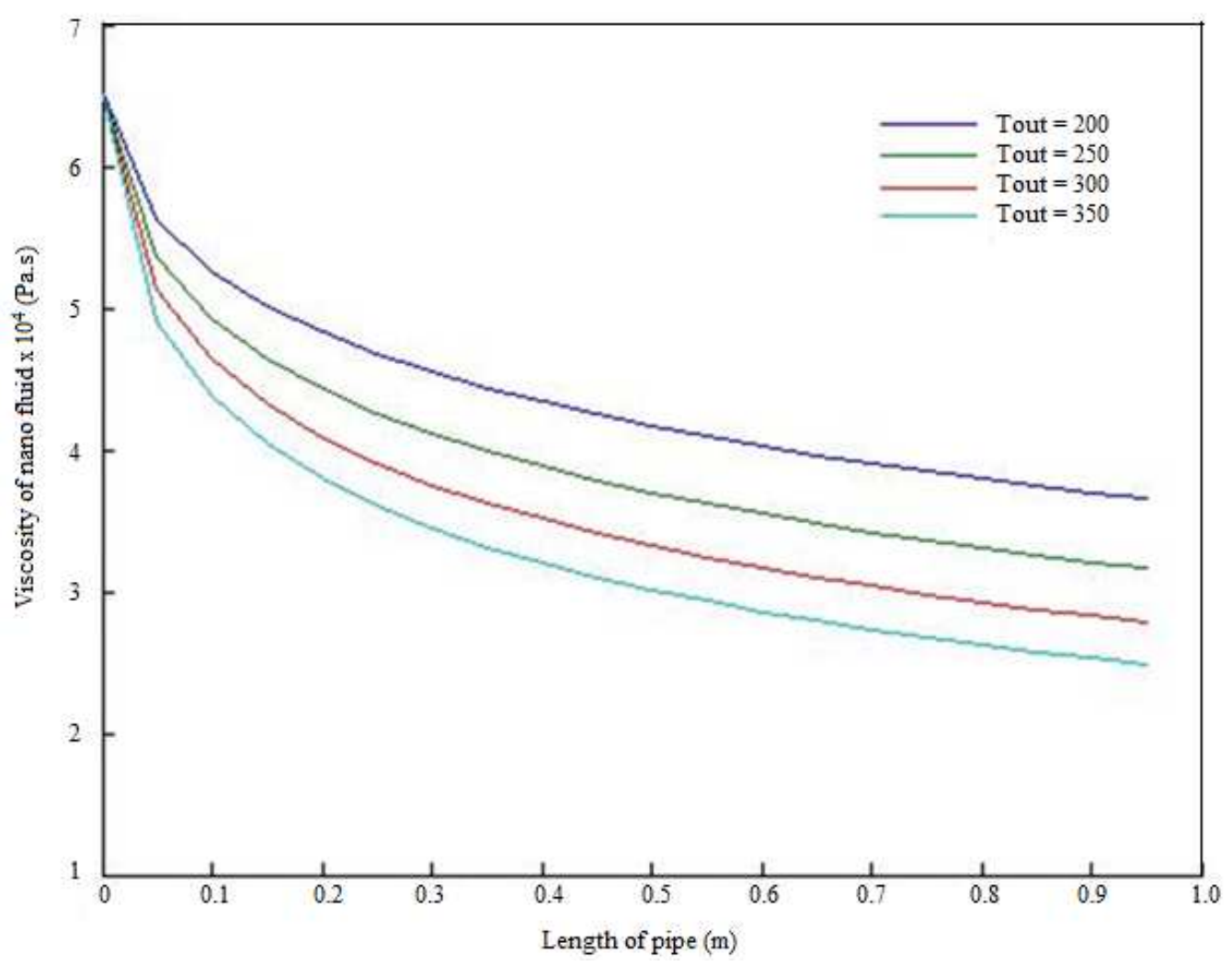

Fig. 9. Viscosity of nanofluids with length 


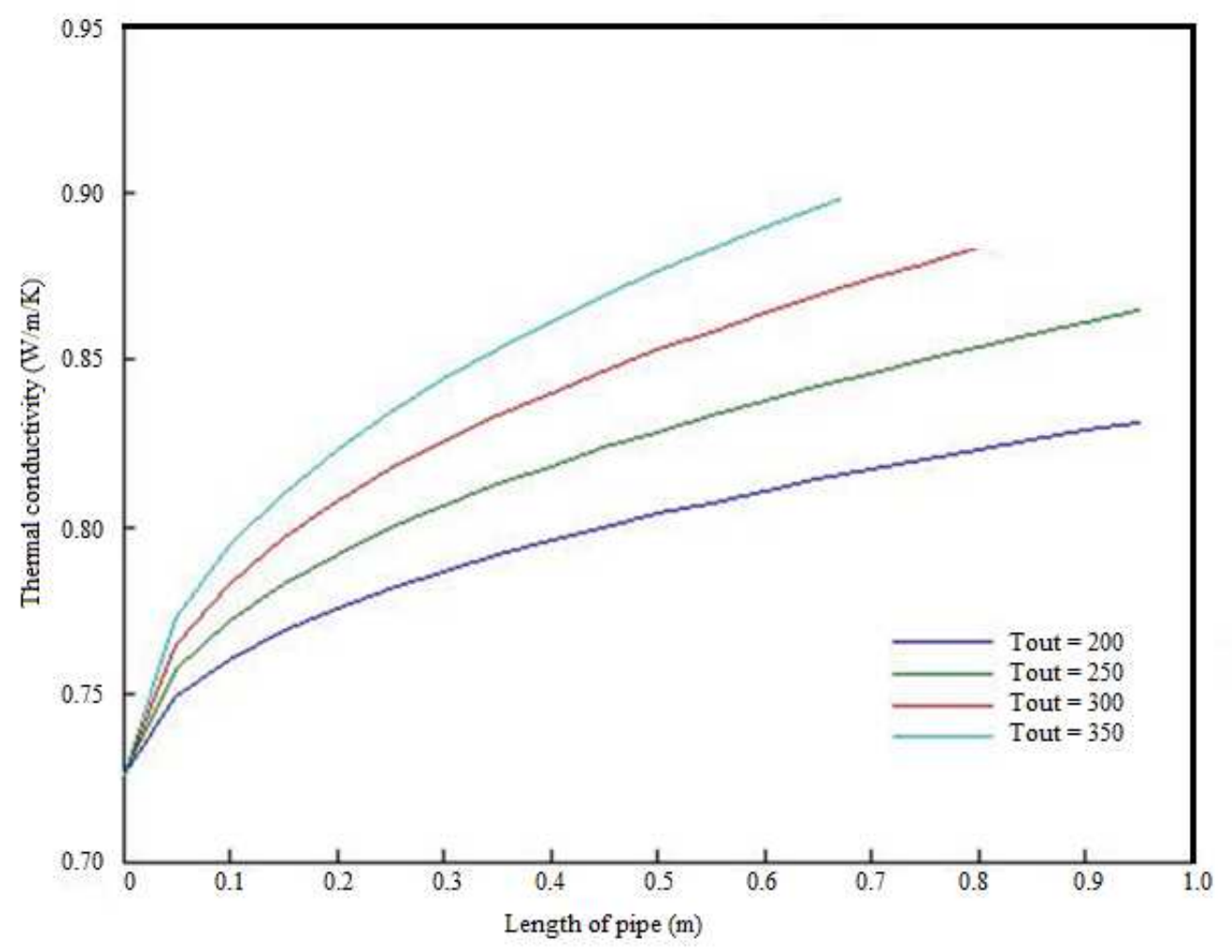

Fig. 10. Thermal conductivity with length

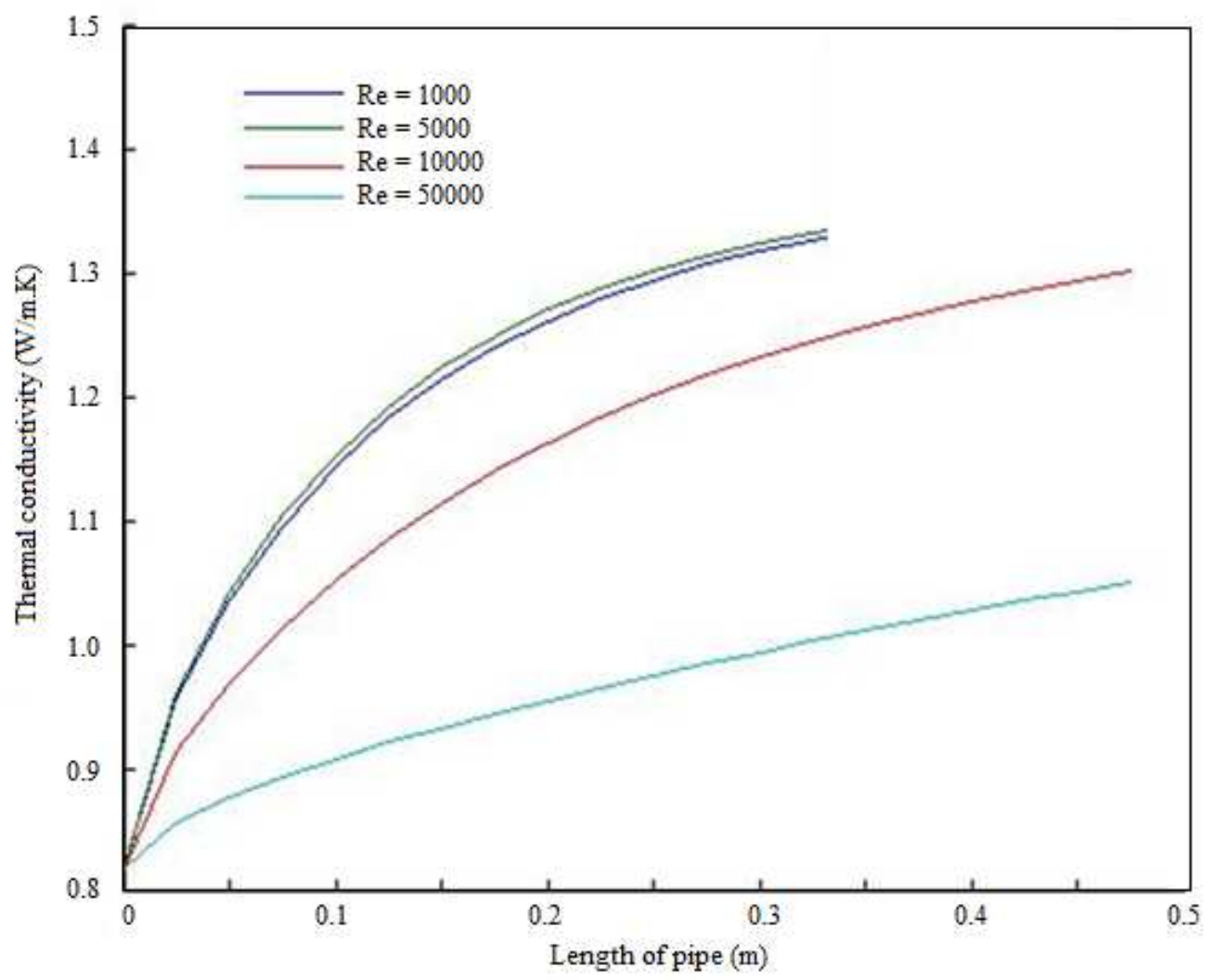

Fig. 11. Thermal conductivity of nanofluid with respect to length 


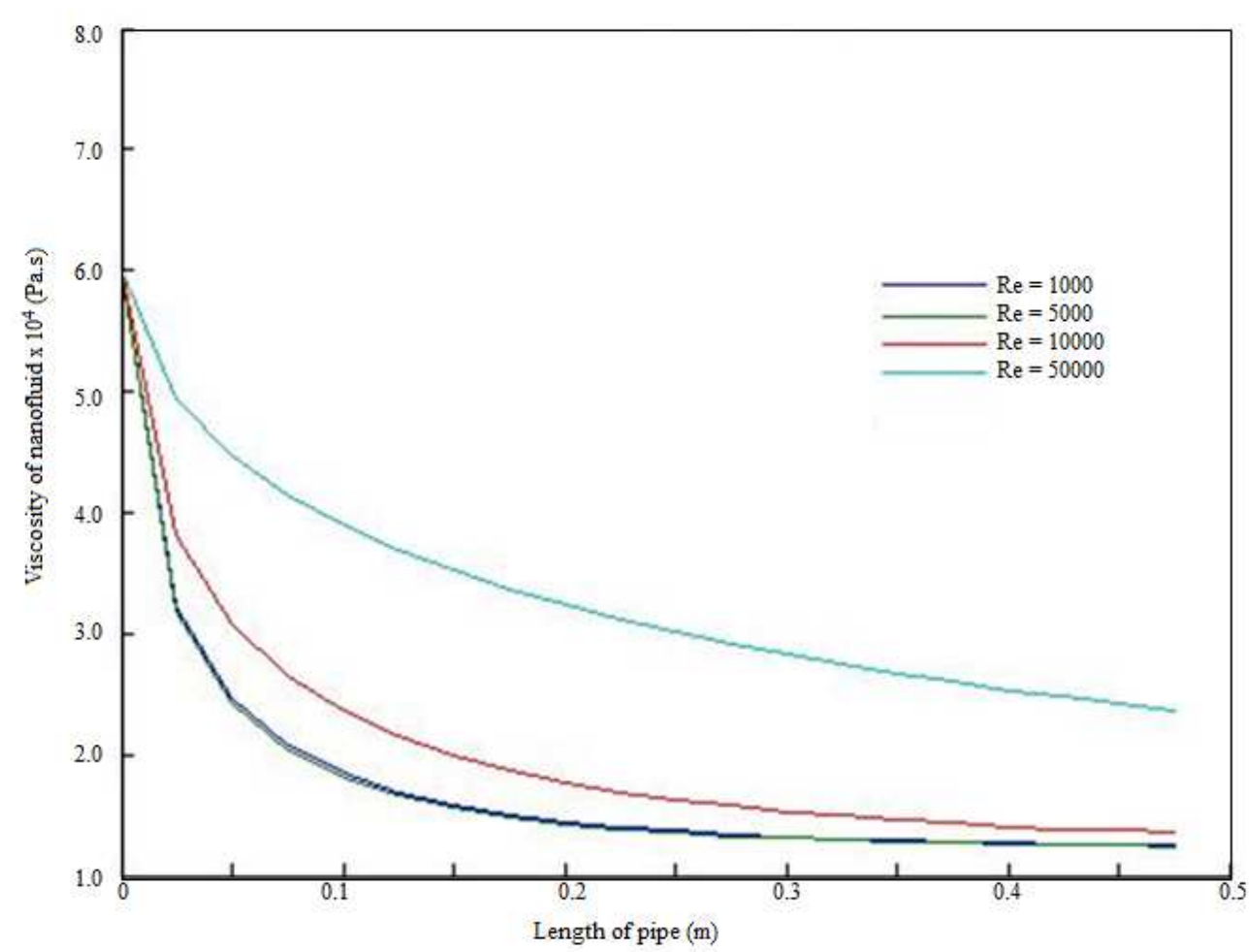

Fig. 12. Viscosity change with respect to length

\section{Conclusion}

Numerical study of forced convective heat transfer of nanofluid in laminar entrance region in a horizontal circular tube with constant wall temperature has been presented with using single phase model. The viscosity and thermal conductivity both are increasing with increased volume fraction of nanoparticle. Numerical results have clearly shown that the use of nanofluids can significantly increase heat transfer capabilities of nanofluids even for relatively small particle volume fractions. Nanofluids with higher volume concentration have higher heattransfer enhancement. The enhancement of the convective heat transfer could not be solely attributed to the enhancement of the effective thermal conductivity but also on other factors. The thermal conductivity increases with increasing volume percentage of nanoparticle, increasing outside wall temperature, decreasing radius and increasing Reynolds number of inlet condition. The viscosity increases with increasing volume friction of nanoparticle, increasing radius of pipe, decreasing outside temperature of wall and increasing Reynolds number of inlet condition. Relative enhancement of $\mathrm{h}$ is increased by increasing the nanoparticles concentration for nanofluids. The MATLAB code is employed to solve the flow in pipe using finite difference method. Finally a conclusion is made based on simulation, how the temperature of the nanofluid flow changed with the radial direction and its axial direction is reported. How thermal conductivity, temperature difference on wall, Reynolds number and the viscosity of the nanofluid changed with the length of the pipe is explained based on the present simulation.

\section{Acknowledgement}

The facilities provided by Indian Institute of Technology Guwahati is acknowledged.

\section{Funding Information}

There is no fund for this research provided by any funding agency.

\section{Author's Contributions}

Gajanand Yadav: Mr Gajanand Yadav did the present research and development. He did the simulation and analysis.

Subrata Kumar Majumder: Mr Gajanand Yadav did the research work under the supervision of Prof. S. K. Majumder. Prof Majumder participated in all simulations, coordinated the data-analysis and contributed to the writing of the manuscript.

\section{Ethics}

The present work is not published in its present form in any journal or will not be published in any journal. 


\section{Reference}

Akbarinia, A. and A. Behzadmehr, 2007. Numerical study of laminar mixed convection of a nanofluid in horizontal curved tubes. Applied Thermal Eng., 27: 1327-1337.

DOI: 10.1016/j.applthermaleng.2006.10.034

Akhtari, M., M. Haghshenasfard and M. R. Talaie, 2013. Numerical and experimental investigation of heat transfer of $\alpha-\mathrm{Al}_{2} \mathrm{O}_{3} /$ water nanofluid in double pipe and shell and tube heat exchangers. Numerical Heat Transfer, Part A: Applica., 63: 941-958. DOI: $10.1080 / 10407782.2013 .772855$

Azmi, W.H., K.V. Sharma, P.K. Sarma, R. Mamat and S. Anuar et al., 2014. Numerical validation of experimental heat transfer coefficient with $\mathrm{SiO}_{2}$ nanofluid flowing in a tube with twisted tape inserts. Applied Thermal Eng., 73: 294-304.

DOI: $10.1016 / \mathrm{j}$.applthermaleng.2014.07.060

Beheshti, A., M.K. Moraveji and M. Hejazian, 2015. Comparative numerical study of nanofluid heat transfer through an annular channe. Numerical Heat Transfer, Part A: Applic., 67: 100-117. DOI: $10.1080 / 10407782.2014 .894359$

Celen, A., N. Kayaci, A. Çebi, H. Demir and A.S. Dalkılıç et al., 2014. Numerical investigation for the calculation of $\mathrm{TiO}_{2}$ - water nanofluids' pressure drop in plain and enhanced pipes. Int. Commun. Heat Mass Transfer, 53: 98-108. DOI: 10.1016/j.icheatmasstransfer.2014.02.022

Demir, H., A.S. Dalkilic, N.A. Kürekci, W. Duangthongsuk and S. Wongwises, 2011. Numerical investigation on the single phase forced convection heat transfer characteristics of $\mathrm{TiO}_{2}$ nanofluids in a double-tube counter flow heat exchanger. Int. Commun. Heat Mass Transfer, 38: 218-228. DOI: $10.1016 /$ j.icheatmasstransfer.2010.12.009

Fard, M.H., M.N. Esfahany and M.R. Talaie, 2010. Numerical study of convective heat transfer of nanofluids in a circular tube two-phase model versus single-phase model. Int. Commun. Heat Mass Transfer, 37: 91-97. DOI: 10.1016/j.icheatmasstransfer.2009.08.003

Ghajar, A.J., 2005. Non-boiling heat transfer in gasliquid flow in pipes-a tutorial. J. Brazilian Society Mechanical Sci. Eng., 27: 46-73. DOI: $10.1590 /$ S1678-58782005000100004

Heris, S.Z., M.N. Esfahany and G. Etemad, 2007. Numerical investigation of nanofluid laminar convective heat transfer through a circular tube. Numerical Heat Transfer, Part A: Applic., 52: 1043-1058. DOI: 10.1080/10407780701364411

Lai, F. and Y. Yang, 2011. Lattice Boltzmann simulation of natural convection heat transfer of $\mathrm{Al}_{2} \mathrm{O}_{3}$ /water nanofluids in a square enclosure. Int. J. Thermal Sci., 50: 1930-1941.

DOI: $10.1016 /$ j.ijthermalsci.2011.04.015
Maxwell, J.C., 1873. A Treatise on Electricity and Magnetism. 1st Edn., Clarendon Press, Oxford, pp: 444.

Namburu, P.K., D.K. Das, K.M. Tanguturi and R.S. Vajjha, 2009. Numerical study of turbulent flow and heat transfer characteristics of nanofluids considering variable properties. Int. J. Thermal Sci., 48: 290-302. DOI: $10.1016 /$ j.ijthermalsci.2008.01.001

Om, N.I. and H.A. Mohammed, 2014. Three-dimensional numerical simulation of mixed convective heat transfer in a horizontal rectangular duct utilizing nanofluids. Adv. Mater. Res., 1016: 738-742. DOI: 10.4028/www.scientific.net/AMR.1016.738

Sarkar, S., S. Ganguly and G. Biswas, 2012. Mixed convective heat transfer of nanofluids past a circular cylinder in cross flow in unsteady regime. Int. J. Heat Mass Transfer, 55: 4783-4799.

DOI: 10.1016/j.ijheatmasstransfer.2012.04.046

Sasmito, A.P., J.C. Kurnia and A.S. Mujumdar, 2011. Numerical evaluation of laminar heat transfer enhancement in nanofluid flow in coiled square tubes. Nanoscale Res. Lett., 6: 1-14. DOI: $10.1186 / 1556-276 X-6-376$

Sheikholeslami, M., M. Gorji-Bandpy, I. Pop and S. Soleimani, 2013. Numerical study of natural convection between a circular enclosure and a sinusoidal cylinder using control volume based finite element method. Int. J. Thermal Sci., 72: 147-158. DOI: 10.1016/j.ijthermalsci.2013.05.004

Sieder, E.N. and G.E. Tate, 1936. Heat transfer and pressure drop of liquids in tubes. Industrial Eng. Chem., 28: 1429-1435. DOI: 10.1021/ie50324a027

Tahir, S. and M. Mital, 2012. Numerical investigation of laminar nanofluid developing flow and heat transfer in a circular channel. Applied Thermal Eng., 39: 8-14. DOI: 10.1016/j.applthermaleng.2012.01.035

Vijay, M.M., M.A. Aggour and G.E. Sims, 1982. A correlation of mean heat transfer coefficients for two-phase two-component flow in a vertical tube. Proc. Int. Heat Transfer Conf., 5: 367-372.

Zhao, N.B., S.Y. Li, J.L. Yang, Z.T. Wang and H. Meng, 2014. Numerical study of laminar flow and convection heat transfer of nanofluids inside circular tube. Adv. Mater. Res., 960: 299-303.

DOI: 10.4028/www.scientific.net/AMR.960-961.299

\section{Nomenclature}

$\mathrm{C}_{\mathrm{p}} \quad$ Specific heat of the fluid, $\mathrm{kJ} / \mathrm{kg}-\mathrm{K}$

$\mathrm{d} \quad$ Diameter of the particle, $\mathrm{nm}$

D Diameter of tube, $m$

h Heat transfer coefficient, W/ $\mathrm{m}^{2}$

$\mathrm{k}$ Thermal conductivity, $\mathrm{W} / \mathrm{m} 2$

$\mathrm{L} \quad$ Length of the tube

$\Delta \mathrm{P} \quad$ Pressure loss, $\mathrm{Pa}$ 
Gajanand Yadav and Subrata Kumar Majumder / Current Research in Nanotechnology 2016, 7 (1): 1.12 DOI: 10.3844/ajnsp.2016.1.12

\begin{tabular}{llll}
$\mathrm{r}$ & Radial distance, $\mathrm{m}$ & \multicolumn{2}{l}{ Superscript } \\
$\mathrm{R}$ & Radius of pipe, $\mathrm{m}$ & $\mathrm{bf}$ & base fluid \\
$\mathrm{Re}$ & Reynolds number & in & inlet \\
$\mathrm{T}$ & Temperature of fluid, ${ }^{\circ} \mathrm{C}$ & $\mathrm{f}$ & fluid \\
$\mathrm{V}$ & Velocity, $\mathrm{m} / \mathrm{s}$ & $\mathrm{m}$ & mass \\
$\mathrm{x}$ & Axial distance from the entrance region of tube, & $\mathrm{np}$ & nanoparticles \\
$\mathrm{m}$ & & $\mathrm{nf}$ & nanofluid \\
$\mathrm{z}$ & z-direction distance, $\mathrm{m}$ & out & outlet \\
Greek & Symbols & $\mathrm{p}$ & $\begin{array}{l}\text { particle } \\
\text { the } \mathrm{q}^{\text {th }} \text { phase (represent liquid and solid phase) }\end{array}$ \\
$\rho$ & Density, $\mathrm{kg} / \mathrm{m}$ & $\mathrm{q}$ & \\
$\Phi$ & Volume concentration, $\%$ & & \\
$\mu$ & Dynamic viscosity, $\mathrm{kg} / \mathrm{m}-\mathrm{s}$ & &
\end{tabular}

